\title{
Combining DNA sequences and morphology in systematics: testing the validity of the dragonfly species Cordulegaster bilineata
}

\author{
EM Pilgrim ${ }^{1,2}$, SA Roush ${ }^{1}$ and DE Krane ${ }^{1}$ \\ ${ }^{1}$ Department of Biological Sciences, Wright State University, Dayton, OH 45435, USA
}

\begin{abstract}
Morphological and molecular techniques are rarely combined when answering questions of taxonomic validity. In this study, we combine morphological techniques with DNA sequences to determine the validity of the dragonfly species Cordulegaster bilineata. The two dragonfly species $C$. bilineata and $C$. diastatops are very similar in size, body color, and morphological characters, and due to these similarities, the status of $C$. bilineata as a valid species is in question. In this study we compare morphological measurements of males and internal transcribed spacer 1 (ITS-1) sequences of rDNA between the two taxa. The hamule measurements (where copulation occurs) of males show little difference between the taxa in question, but the anal appendage measurements (where the male first contacts the female) show marked divergence between the two taxa. Cluster analysis with these anal appendage measurements correctly assigns almost all individuals measured into their respective
\end{abstract}

taxon. PCR amplification products of ITS-1 display a $\sim 50 \mathrm{bp}$ size difference between $C$. bilineata $(n=4)$ and $C$. diastatops $(n=5)$ regardless of collection site. Sequence data for these amplifications show $51 \mathrm{bp}$ missing in one locus in the ITS-1 of $C$. bilineata relative to $C$. diastatops. A lone population of $C$. diastatops from Wisconsin has three individuals with ITS-1 products that match the size of both $C$. bilineata and $C$. diastatops. One individual from this population appears to yield two ITS-1 amplification products that match both $C$. bilineata and $C$. diastatops. Although this population may be evidence for hybridization between the two taxa, such hybridization is not necessarily sufficient to disqualify the validity of a separate species designation for $C$. bilineata. Morphology and ITS-1 sequences depict a high degree of divergence that is consistent with species-level differences. Heredity (2002) 89, 184-190. doi:10.1038/sj.hdy.6800112

Keywords: Cordulegaster, ITS; rDNA; Cordulegastridae; Odonata; morphology

\section{Introduction}

Invertebrates often present special challenges to taxonomic studies. Species-level complications such as cryptic species and species complexes have become more apparent. Groups such as mites (Navajas et al, 1997), ticks (Wesson et al, 1993), and parasitic nematodes (Hung et al, 1997; Hoste et al, 1998) often lack sufficient morphological characters to allow for simple taxonomic comparison and identification. Many insect groups also share this lack of useful anatomical characters to aid in identification, including Homoptera (Cenis et al, 1993; Garcia, et al, 1998), Diptera (Wilkerson et al, 1995; Morrow et al, 2000), and Hymenoptera (Silva et al, 1999; Taylor and Szalanski, 1999). Molecular methods are becoming more useful and important as the need for taxonomic identification increases for many insect species due to their economic (Cenis et al, 1993) and medical (Wilkerson et al, 1995) and potential conservation significance. The 'lock and key' hypothesis, a staple of insect taxonomic work, where the fit of genitalia is thought to be strong evidence for distinc-

Correspondence: EM Pilgrim

${ }^{2}$ Current address: Department of Biology, Utah State University, Logan, UT 84322, USA. E-mail: anisopteran@biology.usu.edu.

Received 25 April 2001; accepted 10 April 2002 tion between species (Sota and Kubota, 1998), has become less credible in insect taxonomy (Porter and Shapiro, 1990), further complicating matters.

Purely morphological research in invertebrate taxonomic research is becoming rare (Leong and Hafernik, 1992; Lamberti and Ciancio, 1993; Verdyck et al, 1998) as molecular techniques become more popular. Techniques such as allozymes (Orr et al, 1994), RAPD-PCR (Wilkerson et al, 1995), RFLPs (Taylor and Szalanski, 1999) and DNA sequencing (Morrow et al, 2000) have all allowed researchers to look beyond morphological similarities and search for genetic differences that may help to solve taxonomic questions. Unfortunately, tension between molecular and morphological researchers has made studies that combine morphology and molecular analysis uncommon (eg, Orr et al, 1994; Navajas et al, 1997; Brust et al, 1998; Manguin et al, 1999; Raahauge and Kristensen, 2000).

In this study, we combine morphological and DNA sequencing approaches to address a question of taxonomic validity between two species of dragonflies (Odonata: Anisoptera), C. bilineata and C. diastatops. Since the separate designation of $C$. bilineata relative to $C$. diastatops (Carle, 1983), the status of C. bilineata as a true species has been in doubt (Glotzhober, 1997). The two species are very similar with only slight differences in 
body color, thoracic stripe width, and some minor morphological characters. These slight distinctions could be the result of simple variation within characters, environmental effects, or geographic variation within $C$. diastatops (Glotzhober, 1997). In the description of C. bilineata, Carle (1983) also places C. diastatops, C. bilineata, and a third species, C. sayi, into a restored genus, Zoraena. Our work does not address the validity of resurrecting the genus Zoraena, as other researchers have already considered it to be a synonym of Cordulegaster (Paulson and Dunkle, 1999). This study focuses only on the validity of C. bilineata as a separate species from C. diastatops.

The unique method of mating in odonates (see Corbet, 1999 for a review) creates some interesting issues when searching for morphological distinction between species. In dragonflies, the male uses the anal appendages on the tip of his abdomen (10th segment) to grasp the female's thorax. Mating then takes place as the female brings her abdomen underneath the male to contact the hamule region near the base of his abdomen (2nd and 3rd segments) where sperm transfer then occurs. In male odonates, the anal appendages and/or the hamules can be species specific (Corbet, 1999). Any taxonomic work on odonate species must include a careful consideration of both of the morphological regions involved with mating.

The purpose of this study is to integrate morphological measurements and DNA sequences as tools of taxonomy. This study is the first to combine morphological characters with DNA sequence data in species-level dragonfly taxonomy and has several objectives. First, we compare morphological measurements of both the anal appendages and the hamule region to look for potential divergence between $C$. bilineata and $C$. diastatops. As both of these structures are involved with copulation, we would expect selection pressure, sexual selection (Eberhard, 1985) or even drift to create divergence between two valid species in one or both of these regions. Second, we compare sequences of the first internal transcribed spacer region (ITS-1) of nuclear rDNA for differences between the two taxa. Although much of the molecular work in taxonomy has been concerned with mitochondrial genes (Simon et al, 1994), the ITS regions are becoming more popular as species-level divergence is common within these regions of DNA (Kuperus and Chapco, 1994; Silva et al, 1999). The final objective of this work is to combine both the morphological and genetic data to uphold or refute the validity of $C$. bilineata as a legitimate species.

\section{Methods}

\section{Morphological data collection}

In order to look for potential morphological differences between the two taxa, we measured 11 different male characters used either in gripping the female or in copulation. Male dragonflies are more common than females in collections and often have more useful characters for species determination (Leong and Hafernick, 1992). Corresponding female characters may exist on their thorax, but the number of female specimens was so low that comparison was not possible (less than 10 specimens total between the two taxa). We measured 70 specimens of $C$. bilineata from a large geographic range (Figure 1) that included several paratype specimens from the original

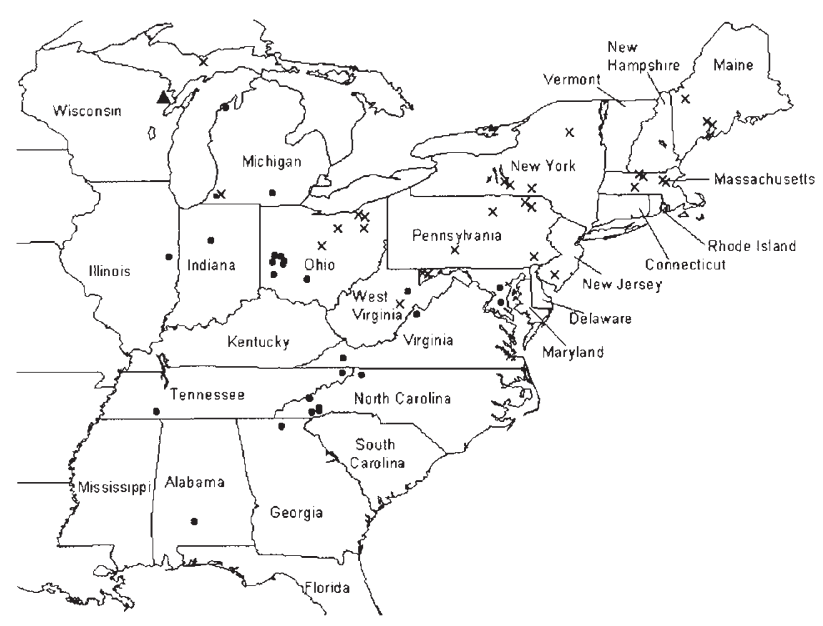

Figure 1 Map of collection sites from the eastern United States. Closed circles show the spread of Codulegaster bilineata sites, and $X^{\prime}$ 's show the spread of $C$. diastatops sites. The large, black triangle marks the 'problematic' Wisconsin population.

description of C. bilineata. We also measured 40 specimens of $C$. diastatops from a similarly sized geographic range (Figure 1). Specimens were identified using the key in Carle (1983) that uses morphological and color characters.

These measurements included six from the hamule region of abdominal segments two and three (where copulation occurs) and five measurements of the anal appendages (used to grasp the female prior to copulation) of segment 10 (Figure 2). The characters chosen also had the advantage of not being obscured from view by other structures. All measurements were made with an ocular micrometer on a dissecting scope and were estimated to the nearest half division (36.8 microns per division). Several structures are paired in

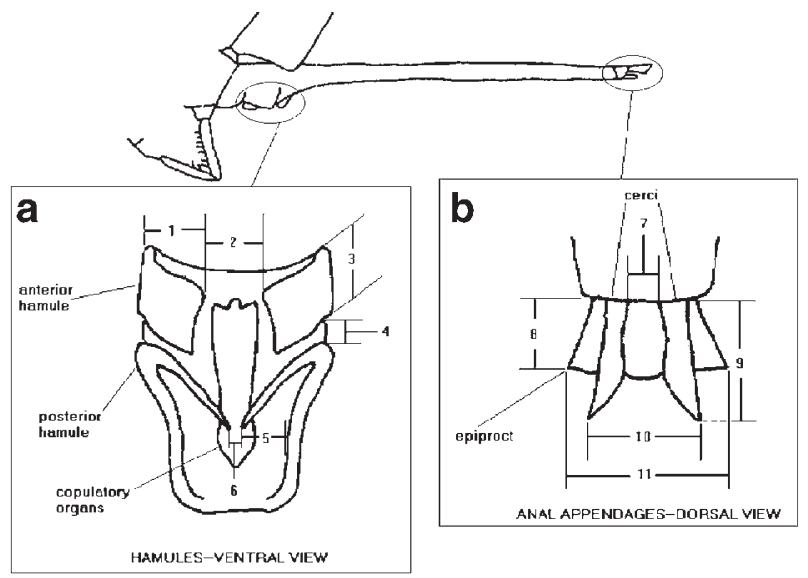

Figure 2 Morphological traits measured in Cordulegaster bilineata and $C$. diastatops. Both species are of similar body size. The hamule measurements (a) consisted of anterior hamule length (1) (AHL), anterior hamule to hamule distance (2) (AHHD), anterior hamule width (3) (AHW), anterior to posterior hamule distance (4) (APHD), posterior hamule distance from the genital fossil wall (5) (PHW), and the posterior hamule to hamule distance (6) (PHHD). The anal appendage measurements (b) consisted of the cercus to cercus proximal distance (7) (CPW), epiproct length (8) (EL), cerci length (9) (CL, cercus to cercus distal width (10) (CDW), and the epiproct width (11) (EDW). 
individuals (cerci, anterior and posterior hamules), so right and left measurements were averaged to give a mean value for that individual. Morphological data were compared with $t$-tests and cluster analysis (UPGMA) using SAS software (v. 8.1).

\section{Genetic data collection}

High molecular weight genomic DNA was isolated from measured specimens and from several female specimens. For comparison against other members of the genus Cordulegaster, one individual each of C. maculata and C. erronea were also included. DNA was isolated from a leg of each individual using the QIAamp DNA Minikit following the Tissue Protocol (QIAGEN, Valencia, CA, USA). DNA samples were stored in the kit's buffer at $4^{\circ} \mathrm{C}$ until needed for polymerase chain reaction (PCR). Older museum specimens (before 1980) often failed to yield useful DNA for PCR amplification.

PCR took place in $20 \mu \mathrm{L}$ volumes with reaction conditions of $10 \mathrm{mM}$ Tris- $\mathrm{HCl}, 50 \mathrm{mM} \mathrm{KCl}, 0.1 \%$ Triton X100 (Promega Mg Free commercial buffer), $3 \mathrm{mM} \mathrm{MgCl}$, 200 pM dNTPs, and 2 units of Promega Taq polymerase. Amplification was accomplished using primers 5'-TCAA CACGGGACCCAGGCCC-3' (forward-18S) and 5'CGATGATCAAGTGTCCTGCA-3' (reverse-5.8S) to amplify the entire ITS-1 region. The $18 \mathrm{~S}$ primer was developed comparing sequences of Aeshna cyanea from GenBank (accession no. X89481) with Macromia taeniolata (unpublished), while the 5.8S primer was developed solely from $M$. taeniolata. The reaction program was 1 cycle at $95^{\circ} \mathrm{C}$ for $3 \mathrm{~min}, 56^{\circ} \mathrm{C}$ for $20 \mathrm{sec}$, and $72^{\circ} \mathrm{C}$ for 35 sec followed by 34 cycles of $95^{\circ} \mathrm{C}$ for $30 \mathrm{sec}, 56^{\circ} \mathrm{C}$ for 20 sec, and $72^{\circ} \mathrm{C}$ for $35 \mathrm{sec}$ and a final extension of $72^{\circ} \mathrm{C}$ for $10 \mathrm{~min}$. Amplification products were size fractionated on 1.5-2.0\% agarose gels stained with ethidium bromide.

Sequencing reactions were performed with the ATBI Big Dye Terminator Cycle Sequencing Ready Reaction Kit from PE Applied Biosystems. The reactions followed the protocols outlined in the accompanying manual using purified PCR product ( $~ 90 \mathrm{ng})$ and an internal primer (5'GATTAGGTCCCTGCCCTTTG-3'). After ethanol precipitation, sequencing reactions were run through an $\mathrm{ABI}$ Prism 310 Genetic Analyzer. Generated sequences were aligned with CLUSTAL W 1.8 (Thompson et al, 1994). Nucleotide sequences for the ITS-1 of all taxa have been submitted to GenBank (accession nos. AY082597 to AY082601).

\section{Results}

\section{Morphological measurements}

Both the hamule and anal appendage measurements show high variation among and within the two taxa, as evident by the minimums, maximums, and standard deviations (Table 1). Satterthwaite $t$-tests (accounting for unequal variance) of all measurements show significant differences between the two taxa for AHW and PHW of the hamule measurements, and for all the anal appendage measurements (Table 1). As the data for some measurements did not fit a normal distribution, we used Wilcoxon Rank Sum test to check for significant differences between the two taxa. The same measurements from the $t$-test also show significant differences in the Wilcoxon Rank Sum test. Transforming the data did not give a normal distribution as several individuals often had identical values for any one measurement. The nonnormal distribution of some measurements is most likely an artifact of the method of measurement (ocular micrometer), but the sample size of each measurement is large enough for the $t$-tests to be a valid comparison of the data sets.

We also used several different combinations of measurements in cluster analysis (UPGMA). No real differences were shown between $C$. diastatops and $C$. bilineata using only the hamule measurements. Individuals of both taxa are spread throughout the cluster dendrogram with no real pattern. When we used all the measurements in the analysis, the dendrogram has two clusters with $C$. bilineata individuals in one and a second cluster with $C$. diastatops individuals nested within a second cluster of C. bilineata individuals. Using only the anal appendage measurements, however, shows a large degree of morphological divergence between $C$. bilineata and $C$. diastatops (Figure 3). Each taxon forms its own cluster within the dendrogram with the exception of two stray individuals of $C$. diastatops that appear within the $C$. bilineata cluster. Using only the measurements EDW, CL, and CDW creates an identical dendrogram of divergence between the two groups.

In the original description of C. bilineata, Carle (1983) mentions that the ratio of EDW to CL is often below 1.3 for C. bilineata and greater than 1.3 for C. diastatops. Over $95 \%$ of the C. bilineata individuals of measured (67 of 70) have an EDW to CL ratio below 1.35 (mean: 1.19, mode: 1.23, median: 1.19). For C. diastatops, almost $95 \%$ of the individuals measured (36 of 38) have a ratio of 1.35 or above (mean: 1.57, mode: 1.63, median: 1.56$)$.

\section{ITS-1 sequences}

PCR amplification and gel electrophoresis revealed a size difference of approximately 50 base pairs (bp) between C. diastatops and C. bilineata (Figure 4a). The only individuals with successful amplifications that did not conform to this size difference were three individuals from Spur Lake, WI (Figure 4b). These individuals were originally classified as $C$. diastatops, however, one individual had a band whose size corresponded to $C$. bilineata, one individual had a band that corresponded to $C$. diastatops, and one individual appears to have two bands that match both taxa. Otherwise, this size difference was apparent for 29 different individuals of $C$. bilineata and for 16 individuals of $C$. diastatops, all from a wide geographic range.

Sequence data for the $18 \mathrm{~S}$ portion of the Cordulegaster species matched very closely with the Aeshna cyanea sequence (only four differences in over $500 \mathrm{bp}$ of $18 \mathrm{~S}$ sequence prior to the ITS-1). ITS sequences ranged in size from 271 to $336 \mathrm{bp}$ for the four species of Cordulegaster, with $271 \mathrm{bp}$ for C. bilineata, $286 \mathrm{bp}$ for C. maculata, 323 to $327 \mathrm{bp}$ for $\mathrm{C}$. diastatops, and $336 \mathrm{bp}$ for $\mathrm{C}$. erronea. The four different individuals of $C$. bilineata (one from IL, two from different sites in $\mathrm{OH}$, and one from MI) had identical ITS1 sequences. Of the five individuals of $C$. diastatops sequenced, individuals from NY and MA had identical sequences, but one individual from $\mathrm{MD}$ has an extra GAGA relative to the other $C$. diastatops sequences (Figure 5).

Alignment of the ITS sequences (Figure 5) showed that the size difference between the PCR products of $C$. bilineata and $C$. diastatops was due to $51 \mathrm{bp}$ missing from a 
Table 1 Morphological character summary statistics for Cordulegaster bilineata and C. diastatops

\begin{tabular}{|c|c|c|c|c|c|c|c|c|c|c|}
\hline \multirow[t]{2}{*}{ Meas. } & \multicolumn{4}{|c|}{ C. bilineata } & \multicolumn{4}{|c|}{ C. diastatops } & \multicolumn{2}{|c|}{ Satterwaite t-test } \\
\hline & $n$ & Mean & $S D E V$ & Coef. Var. & $n$ & Mean & $S D E V$ & Coef. Var. & $d f$ & $P$ value \\
\hline AHL & 70 & 878 & 44.0 & 0.050 & 40 & 890 & 38.5 & 0.043 & 103 & 0.1391 \\
\hline AHW & 70 & 822 & 152.3 & 0.185 & 40 & 731 & 107.5 & 0.147 & 90.5 & $0.0004^{*}$ \\
\hline APHD & 70 & 135 & 106.7 & 0.790 & 40 & 113 & 72.8 & 0.644 & 104 & 0.2001 \\
\hline PHW & 70 & 649 & 115.3 & 0.178 & 38 & 587 & 119.4 & 0.203 & 73.8 & 0.0103 \\
\hline AHHD & 70 & 764 & 141.2 & 0.185 & 40 & 718 & 136.4 & 0.190 & 83.7 & 0.0910 \\
\hline PHHD & 70 & 388 & 73.4 & 0.189 & 38 & 389 & 98.4 & 0.253 & 59.8 & 0.9271 \\
\hline EDW & 67 & 1819 & 95.7 & 0.053 & 40 & 2056 & 106.6 & 0.052 & 75.3 & $<0.0001^{*}$ \\
\hline $\mathrm{EL}$ & 69 & 954 & 109.0 & 0.114 & 40 & 1022 & 112.7 & 0.110 & 79.4 & $0.0030^{*}$ \\
\hline CL & 67 & 1535 & 90.8 & 0.059 & 36 & 1319 & 79.4 & 0.060 & 80.4 & $<0.0001^{*}$ \\
\hline CPW & 68 & 753 & 84.7 & 0.112 & 39 & 897 & 118.4 & 0.132 & 60.6 & $<0.0001^{*}$ \\
\hline CDW & 63 & 673 & 220.5 & 0.328 & 30 & 1103 & 203.6 & 0.185 & 61.8 & $<0.0001^{*}$ \\
\hline
\end{tabular}

*Denotes significance at Bonferroni corrected $P=0.0045$.

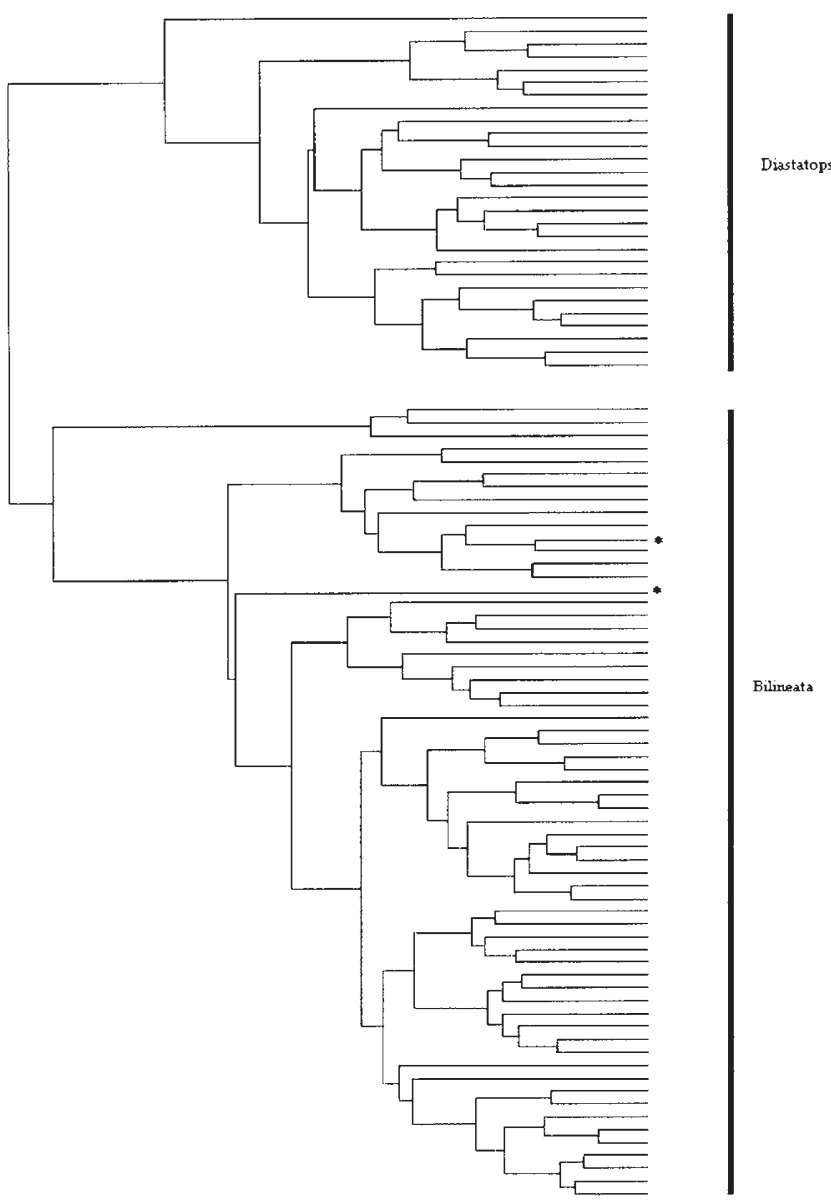

Figure 3 Cluster dendrogram of Cordulegaster bilineata and C. diastatops individuals using anal appendage measurements (EDW, EL, $\mathrm{CL}, \mathrm{CPW}$, and CDW). Two individuals of $C$. diastatops within the C. bilineata cluster are marked with asterisks.

single portion of the ITS-1 of $C$. bilineata relative to $C$. diastatops. Two $\mathrm{T}$ to $\mathrm{G}$ transversions and a $\mathrm{C}$ to $\mathrm{T}$ transition also existed between the two taxa. Comparison to the other two Cordulegaster species suggested that the missing $51 \mathrm{bp}$ in $C$. bilineata most likely resulted from a deletion of those base pairs.

\section{Discussion}

Clearly, C. bilineata and C. diastatops have diverged morphologically. The contrast between morphology of the two cannot be explained by overall body size variation, as $C$. bilineata and $C$. diastatops are very similar in size. The two taxa may have similar hamule characteristics, but the anal appendage measurements of each species show large differences between the two. The high significance in several $t$-tests $(P<0.0001)$ in anal appendage measurements speaks to the degree of morphological divergence that exists between $C$. bilineata and $C$. diastatops. The divergence in anal appendages between morphologically similar species is not unusual, as these appendages are the first parts of the male that contact the female prior to mating (Corbet, 1999). Females odonates are known to reject males of other species based on this type of contact (Corbet, 1999). The EDW to CL ratio shows that almost all $C$. bilineata fall below the critical value of 1.35 and that most $C$. diastatops are above this value. When all the anal appendage measurements are taken as a group in cluster analysis, the degree of divergence between $C$. bilineata and $C$. diastatops becomes even more evident. The two taxa are also genetically distinct as shown by their ITS- 1 sequences. The 51-bp deletion is striking evidence of genetic divergence between C. bilineata and $C$. diastatops. A transition and two transversions in the ITS-1 sequences are also significant evidence for genetic distance between $C$. bilineata and C. diastatops.

Although the morphological evidence alone may only be enough to relegate $C$. bilineata to subspecific status, the morphological differences coupled with the genetic data strongly suggest that $C$. bilineata be accepted as a valid species. Differences similar to that between $C$. bilineata and $C$. diastatops exist between other, well-accepted species of aphids and wasps (Fenton et al, 1998; Silva et al, 1999). ITS-1 sequence differences have been reported within a single species over a large geographic area (Vogler and DeSalle, 1994). The sequence differences between $C$. bilineata and $C$. diastatops, however, do not fit this pattern of within-species variation. The size difference in ITS-1 product remains constant for each taxon over a large geographic area (except for the three Wiscon$\sin$ (WI) individuals). The individuals sequenced for $C$. bilineata come from a wide geographic range (Illinois to 
a

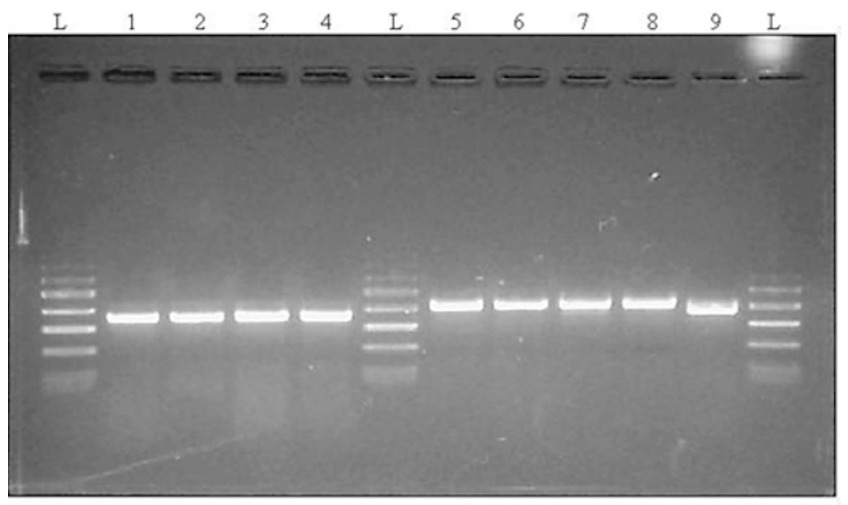

b

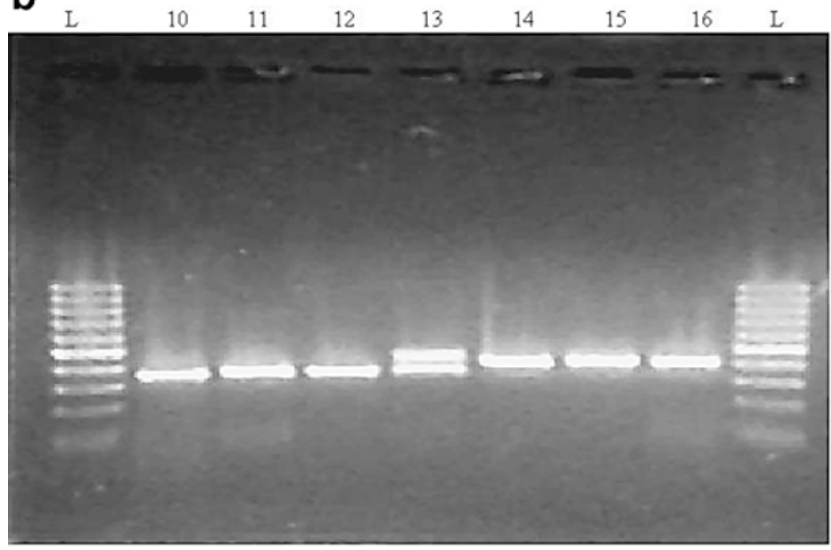

Figure 4 Gel electrophoresis photos of ITS-1 PCR amplifications. Lanes marked 'L' are DNA markers in $100 \mathrm{bp}$ increments (100 to 1000 bp). (a) Comparison of Cordulegaster bilineata and C. diastatops ITS-1 products. Lane $1-C$. bilineata (Gallagher Fen, Ohio $(\mathrm{OH})$ ), Lane $2-C$. bilineata (Freeman Property, Michigan (MI)), Lane 3 C. bilineata (Forest Glen, Illinois), Lane $4-C$. bilineata (Kiser Lake, $\mathrm{OH}$ ), Lane $5-\mathrm{C}$. diastatops (Barre Dam, Massachusetts (MA)), Lane $6-C$. diastatops (E. Branch Reservoir, $\mathrm{OH}$ ), Lane $7-$ C. diastatops (Shingleton, MI), Lane $8-C$. diastatops (The Glades, Maryland (MD)). Lane 9 is the ITS-1 product of a third species, C. maculata. Notice the $\sim 50$ bp size difference between $C$. bilineata and $C$. diastatops. (b) Comparison of problematic Wisconsin (WI) population. Lane $10-C$. bilineata $(\mathrm{OH})$, Lane $11-C$. bilineata (Alabama), Lane 12 - Male 1 from Spur Lake, WI, Lane 13 - Male 2 from Spur Lake, WI, Lane 14 - Female from Spur Lake, WI, Lane 15 - C. diastatops (Pennsylvania), Lane $16-C$. diastatops (MA). Male 1 has an ITS-1 product of similar size to C. bilineata. The female specimen matches the ITS- 1 product of $C$. diastatops. Male 2 appears to have ITS-1 products that match both $C$. bilineata and C. diastatops.

Ohio to Michigan) and show no sequence variation. The sequenced individuals of $C$. diastatops come from a similarly sized geographic area (Maryland, New York, New Jersey, and Massachusetts) and show only slight sequence variation (an extra GAGA near the region missing relative to $C$. bilineata).

This variation in $C$. diastatops near the $51 \mathrm{bp}$ missing from $C$. bilineata may explain how this deletion could have occurred. The ITS-1 sequence upstream and downstream of the deletion is rich in A and G. The AG rich areas on both sides of the deletion could have led to unequal crossing over or could have caused slippage during replication that excised the $51 \mathrm{bp}$. Molecular drive would have spread the deletion to other copies of the

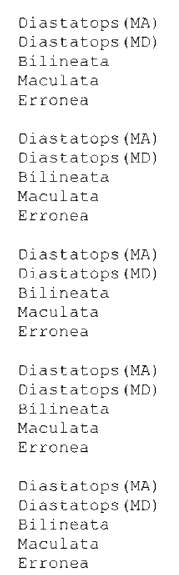

Diastatops (MA)

Diastatops (MD)

Bilineata
Maculata

Maculata

Figure 5 Alignment of ITS-1 sequences $\left(5^{\prime}-3^{\prime}\right)$ of Cordulegaster diastatops $(\mathrm{MA})(n=4), C$. diastatops $(\mathrm{MD})(n=1), C$. bilineata $(n=4), C$. maculata $(n=1)$, and C. erronea $(n=1)$. Notice AG rich areas before and after the $51 \mathrm{bp}$ missing from $C$. bilineata.

gene (Dover, 1982). Alignment of the ITS-1 sequences of the four different species of Cordulegaster also shows that the most of the variation between all four taxa occurs in this particular portion of the ITS- 1 and suggests that this region of the ITS-1 is quite variable.

The lone WI population may represent a problem for determining species status of these taxa, since different individuals within this population have ITS-1 products representative of both taxa. Under a strict interpretation of the biological species concept, the individual that appears to have both size ITS- 1 bands would be strong evidence for hybridization between $C$. bilineata and $C$. diastatops, sinking $C$. bilineata as a separate species. This evidence for hybridization is quite tenuous, as it only includes three individuals with only one showing both ITS-1 bands. Hybridization between insect species, however, does not necessarily suggest high levels of gene flow between taxa as differences between species are maintained outside the hybrid zone (Jiggins et al, 1997; Willet et al, 1997). The presence of both bands could also be caused by incomplete homogenization of the deletion in the ITS-1 region throughout the genome.

Even if we assume that this evidence is sufficient to demonstrate interbreeding between C. bilineata and $C$. diastatops, several reasons exist to suggest that $C$. bilineata be considered a valid species. First, we have no way of knowing the fitness of the dual ITS band individual (although it did reach adulthood) or if it had the ability to produce viable offspring. Second, hybridization is known to occur between well-accepted, separate species of other insects, including crickets (Willet et al, 1997), butterflies (Jiggins et al, 1997), and damselflies (Leong and Hafernik, 1992). Male dragonflies are well known for their lack of discrimination when attempting copulation, as reports of copulation attempts with females of different species, genera, and even families are known to occur (Bick and Bick, 1981; Corbet, 1999). Finally, these three individuals from a single population simply do not represent enough data to support the idea that $C$. bilineata and $C$. diastatops readily hybridize. The combination of 
both morphological and DNA sequence data is strong enough for the distinction of $C$. bilineata and $C$. diastatops as separate species to be maintained.

Unfortunately, we were unable to find morphological characters that will always conclusively distinguish between the two species. Color characters are used extensively in the original description of C. bilineata (Carle, 1983), but these characters are quite subjective. Cordulegaster bilineata is described as having a brown body with thinner thoracic stripes to that of the blacker $C$. diastatops (Carle, 1983). This distinction, however, is based mainly on museum specimens whose colors could be influenced by their age when captured, how they were preserved, and how long ago they were collected. We chose to eliminate color characters from our analysis because the body color was too difficult to quantify objectively and the thickness of the thoracic stripes was impossible to measure consistently due to the variable edges of these stripes. That color characters of this nature are too vague to be useful in taxonomy was evident in specimens of C. bilineata we collected from western MI. These were very dark and could be confused with $C$. diastatops based on color alone, although their ITS band and their EDW to CL ratio identified them as C. bilineata. Though imperfect, the ratio of EDW to CL seems to be the single best morphological character for determining $C$. bilineata from $C$. diastatops.

This study shows how morphological tools can be combined with DNA sequence data to address questions of species-level taxonomy. As DNA sequencing becomes more readily available, more studies could combine molecular and morphological techniques to address other taxonomic issues. Among C. bilineata and C. diastatops, anal appendage measurements should be predictive in identifying around $95 \%$ of individuals. Adding molecular methods should allow $100 \%$ correct identification between these two taxa. The ability to accurately distinguish between $C$. bilineata from $C$. diastatops is important for study of the distribution and habitat requirements. Although, neither is currently in danger of extinction, neither species is common and both are often known from only a few locations within a given state. The rarity of either species is probably related to their relatively specific habitat requirements of preferring small, forested seeps and streams (often found in bogs or fens, wetland habitats that are becoming increasingly sparse in the eastern United States). Future work with these two species should center on determining the nature of any hybridization or hybrid zone in the WI population and also on using molecular identifications as a tool for finding other more useful morphological characters for ease of distinction between these two similar, but separate species.

\section{Acknowledgements}

We would first like to thank Bob Glotzhober for bringing this project to our attention, as well as for help with specimens and collecting. We also want to thank the following people and organizations for help with specimens and collecting: Tim Cashatt and Tim Vogt at the Illinois State Museum, Mark O'Brien and Ethan Bright at the University of Michigan Museum of Zoology, Bill Mauffray at the Florida State Collection of Arthropods, Andrey Sharkov at the Ohio State University Museum of Biodiversity, Bob Barber, Blair Nikula, Richard Orr, and Carl Freeman.
Thanks to Billy Grunwald Jr. for help with DNA isolation and PCR and to Lori Halsey for help with DNA sequencing. Thanks to Jim Amon and Tim Wood for advice and comments and to Carol von Dohlen, Colin Bremer, Diane Rowe and two reviewers for their comments on this paper.

\section{References}

Bick GH, Bick JC (1981). Heterospecific pairing among Odonata. Odonatologica 10: 259-270.

Burst RA, Ballard JWO, Driver F, Hartley DM, Galway NJ, Curran J (1998). Molecular systematics, morphological analysis, and hybrid crossing identify a third taxon, Aedes (Halaedes) wardangensis sp.nov., of the Aedes (Halaedes) australis speciesgroup (Diptera: Culcidae). Can J Zool 76: 1236-1246.

Carle FL (1983). A new Zoraena (Odonata: Cordulegastridae) from eastern North America, with a key to the adult Cordulegastridae of America. Ann Entomol Soc Am 76: 61-68.

Cenis JL, Fereres A (1993). Identification of aphid (Homoptera: Aphididae) species and clones by Random Amplified Polymorphic DNA. Ann Entomol Soc Am 86: 545-550.

Corbet PS (1999). Dragonflies: Behavior and Ecology of Odonata. Cornell University Press: Ithaca, New York.

Dover G (1982). Molecular drive: a cohesive mode of species evolution. Nature 299: 111-117.

Eberhard WG (1985). Sexual Selection and Animal Genitalia. Harvard University Press: Cambridge, MA.

Fenton B, Malloch G, Germa F (1998). A study of variation in the rDNA ITS regions shows that two haplotypes coexist within a single aphid genome. Genome 41: 337-345.

Glotzhober RC (1997). Odonata of Cedar Bog and other westcentral Ohio fens. Cedar Bog Symposium III-Proceedings, pp 91-96.

Garcia AL, Carrasco HJ, Schofield CJ, Stothard JR, Frame IA, Valente SAS et al (1998). Random amplification of polymorphic DNA as a tool for taxonomic studies of triatomine bugs (Hemiptera: Reduviidae). J Med Entomol 35: 38-45.

Hoste H, Chilton NB, Beveridge I, Gasser RB (1998). A comparison of the first internal transcribed of ribosomal DNA in seven species of Trichostrongylus (Nematoda: Trichostrongylidae). Int J Parasitol 27: 601-605.

Hung GC, Chilton, NB, Beveridge I, McDonnell A, Lichtenfels JR, Gasser RB (1997). Molecular delineation of Cylicocyclus nassatus and C. ashworthi (Nematoda: Strongylidae). Int J Parasit 27: 601-605.

Jiggins CD, McMillan WO, King P, Mallet J (1997). The maintenance of species differences across a Heliconius hybrid zone. Heredity 79: 495-505.

Kuperus WR, Chapco W (1994). Usefulness of internal transcribed spacer regions of ribosomal DNA in melanopline (Orthoptera:Acrididae) systematics. Ann Entomol Soc Am 87: 751-754.

Lamberti F, Ciancio A (1993). Diversity of Xiphinema americumgroup species and hierarchical cluster analysis of morphometrics. J Nemat 25: 332-343.

Leong JM, Hafernik JE, JR (1992). Hybridization between two damselfly species (Odonata: Coenagrionidae): morphometric and genitalic differentiation. Ann Entomol Soc Am 85: 662-670.

Manguin S, Wilkerson RC, Conn JE, Rubio-Palis Y, Danoff-Burg JA, Roberts DR (1999). Population structure of the primary malaria vector in South America, Anopheles darlingi, using isozyme, random amplified polymorphic DNA, internal transcribed spacer 2, and morphological markers. Am. J Trop Med Hyg 60: 364-376.

Morrow J, Scott L, Congdon B, Yeates D, Frommer M, Sved J (2000). Close genetic similarity between two sympatric species of tephritid fruit fly reproductively isolated by mating time. Evolution 54: 899-910.

Navajas M, Gutierrez J, Gotoh T (1997). Convergence of molecular and morphological data reveals phylogenetic information 
on the Tetranychus species and allows the restoration of the genus Amphitetranychus (Acari: Tetranychidae). Bull Entomol Res 87: 283-288.

Orr MR, Porter AH, Mosseau TA, Dingle H (1994). Molecular and morphological evidence for hybridization between two ecologically distinct grasshoppers (Melanoplus sanguinipes and M. devastator) in California. Heredity 72: 42-54.

Paulson DR, Dunkle SW (1999). A Checklist of North American Odonata. Slater Museum of Natural History: University of Puget Sound.

Porter AH, Shapiro AM (1990). Lock-and-Key Hypothesis: lack of mechanical isolation in a butterfly (Lepidoptera: Pieridae) hybrid zone. Ann Entomol Soc Am 83: 107-114.

Raahauge P, Kristensen TK (2000). A comparison of Bulinus africanus group species (Planorbidae; Gastropoda) by use of the internal transcribed spacer 1 region combined by morphological and anatomical characters. Acta Tropica 75: 85-94.

Silva IM, Honda J, Van Kan F, Hu J, Neto L, Pintureau B et al (1999). Molecular differentiation of five Trichogramma species occurring in Portugal. Biol Contr 16: 177-184.

Simon C, Frati F, Beckenbach A, Crespi B, Liu H, Flook P (1994). Evolution, weighting, and phylogenetic utility of mitochondrial gene sequences and a compilation of conserved polymerase chain reaction primers. Ann Entomol Soc Am 87: 651701.

Sota T, Kubota K (1998). Genital lock-and-key as a selective agent against hybridization. Evolution 52: 1507-1513.
Taylor DB, Szalanski AL (1999). Identification of Muscidifurax sp. by polymerase chain reaction-restriction fragment length polymorphism. Biol Contr 15: 270-273.

Thompson JD, Higgins DG, Gibson TJ (1994). Clustal W: improving the sensitivity of progressive multiple sequence alignment through sequence weighting, positions-specific gap penalties and weight matrix choice. Nucleic Acids Res 22: 4673-4680.

Verdyck P, De Bruyn L, Hulsemans J (1998). A morphological study of Phyllotreta tetrastigma (Coleoptera: Chrysomelidae: Alticinae) including two colour forms. J Nat Hist 32: 777-783.

Vogler AP, DeSalle R (1994). Evolution and phylogenetic information content of the ITS-1 region in the tiger beetle Cicindela dorsalis. Mol Biol Evol 11: 393-405.

Wesson DM, McLain DK, Oliver JH, Piesman J, Collins FH (1993). Investigation of the validity of species status of Ixodes dammini (Acari: Ixodidae) using rDNA. Proc Natl Acad Sci 90: 10221-10225.

Wilkerson RC, Parsons TJ, Klein TA, Gaffigan TV, Bergo E, Consolim J (1995). Diagnosis by random amplified polymorphic DNA polymerase chain reaction of four cryptic species related to Anopheles (Nyssorhynchus) albitarsis (Diptera: Culcidae) from Pararguay, Argentina, and Brazil. J Med Entomol 32: 697-704.

Willet CS, Ford MJ, Harrison RG (1997). Inferences about the origin of a field cricket hybrid zone from a mitochondrial DNA phylogeny. Heredity 79: 484-494. 